\title{
Agricultura familiar e produção orgânica: uma análise comparativa considerando os dados dos censos de 1996 e 2006
}

Family farming and organic production: a comparative analysis considering data from census 1996 and 2006

\section{L'agriculture familiale et l'agriculture biologique: une analyse comparative tenant compte des données du recensement de 1996 et 2006}

Agricultura familiar y la agricultura ecológica: un análisis comparativo teniendo en cuenta los datos del censo de 1996 y 2006

\author{
Juliana Benites Padua* \\ (julianabenitespadua@gmail.com) \\ Madalena Maria Schlindwein* \\ (madalenaschlindwein@ufgd.edu.br) \\ Eder Pereira Gomes* \\ (edergomes@ufgd.edu.br)
}

Recebido em 18/04/2012; revisado e aprovado em 30/07/2012; aceito em 01/02/2013

\begin{abstract}
Resumo: Este trabalho tem como objetivo caracterizar a evolução e o desenvolvimento da agricultura familiar no Brasil e no estado de Mato Grosso do Sul, bem como analisar a representatividade da agricultura orgânica nos cenários nacional e regional. Pôde-se constatar a importância da agricultura familiar para o desenvolvimento socioeconômico, porém baixa utilização da agricultura orgânica.

Palavras-chaves: Agricultura Orgânica. Segurança Alimentar. Desenvolvimento.

Abstract: This paper aims to characterize the evolution and development of family agriculture in Brazil and the state of Mato Grosso do Sul, as well as analyze the representativeness of organic agriculture in the national and regional levels. It was found the importance of family farming for socioeconomic development, but low use of organic agriculture.

Key words: Organic Agriculture. Food Security. Development.

Résumé: Cette étude vise à caractériser l'évolution et le développement de l'agriculture familiale au Brésil et l'État du Mato Grosso do Sul, ainsi que d'analyser la représentativité de l'agriculture biologique aux niveaux national et régional. Il a été constaté l'importance de l'agriculture familiale pour le développement socio-économique, mais la faible utilisation de l'agriculture biologique.

Mots-clés: Agriculture biologique. Sécurité alimentaire. Développement.

Resumen: El presente trabajo tiene como objetivo caracterizar la evolución y desarrollo de la agricultura familiar en Brasil y en el estado de Mato Grosso do Sul, así como analizar la representatividad de la agricultura ecológica en los ámbitos nacional y regional. Se encontró la importancia de la agricultura familiar para el desarrollo socioeconómico, pero bajo uso de la agricultura orgánica.

Palabras clave: Agricultura Orgánica. Seguridad Alimentaria. Desarrollo.
\end{abstract}

\section{Introdução}

Durante os anos de 1960 e 1970, a agricultura no Brasil passou por uma intensa transformação em busca da modernização e, conforme aborda Gavioli e Costa (2011), essa inovação, com o apoio estatal, gerou a incorporação de práticas agroquímicas e motomecânicas de produção, de forma que o setor agrícola se integrasse cada vez mais com o setor industrial. Porém essa modernização rural, centrada na preservação da hegemonia da grande propriedade fundiária com a finalidade de aumentar as exportações brasileiras, resultou, segundo Caume (2003), em um modelo de desenvolvimento socialmente excludente e ecologicamente predatório, representando a marginalização social, econômica e política de muitos agricultores familiares que se viram obrigados a migrar para os centros urbanos.

Em vista dos diversos problemas socioambientais gerados pelo modelo de desenvolvimento seguido pelo Brasil, surge

\footnotetext{
* Universidade Federal da Grande Dourados, Dourados, MS, Brasil.
} 
entre meados de 1980 a 1990 a preocupação ambiental. E, insere-se nesse contexto, a idéia da sustentabilidade e a defesa da agricultura familiar como agente fundamental da construção do desenvolvimento do meio rural (GAVIOLI; COSTA, 2011).

A agricultura familiar é de extrema importância para o desenvolvimento econômico do Brasil, assim como de seus estados e municípios, tanto na geração de renda das famílias envolvidas, como na produção de alimentos e na redução do êxodo rural, além do favorecimento do emprego de práticas produtivas ecologicamente mais equilibradas, como a diversificação de cultivos e a diminuição da utilização de insumos industriais. Gomes (2004) destaca essa importância devido às diversas discussões que vem ganhando força, sobretudo considerando os debates embasados no desenvolvimento sustentável e na segurança alimentar.

Tendo em vista a importância do desenvolvimento sustentável e de um mercado com consumidores diferenciados com forte preocupação ambiental e interessados em produtos mais saudáveis, é estimulada a produção de alimentos orgânicos em grande parte dos produtores familiares. Segundo o IPEA (2012), a demanda por produtos orgânicos cresce em torno de $30 \%$ ao ano, sendo que se estima, para o caso do Brasil, que $90 \%$ da produção orgânica seja proveniente da agricultura familiar.

Contudo, diante de todos os arranjos de políticas criadas e direcionadas ao agricultor, nem sempre elas se mostram totalmente eficientes. De acordo com Guilhoto et al. (2006), mesmo com a agricultura familiar mantendo a força e grande representatividade na riqueza do país, os agricultores são penalizados por insuficiências de terras e capital, por dificuldades no financiamento, pela baixa disponibilidade tecnológica, assim como pela fragilidade da assistência técnica.

Entretanto, sabendo da importância e das melhoras atribuídas à agricultura familiar e aos assentados pelas iniciativas governamentais através de políticas públicas, embora algumas delas não estejam conseguindo atender a demanda necessária ocasionando insatisfações por parte de alguns agricultores, surge o questionamento sobre a extensão da produção orgânica obtida através da agricul- tura familiar, mediante os problemas atuais ocasionados pelas deficiências ou falhas das políticas públicas voltadas a esses agricultores familiares.

Nesse contexto, o presente estudo visa caracterizar a evolução e o desenvolvimento da agricultura familiar no Brasil e no estado de Mato Grosso do Sul, com ênfase na agricultura orgânica a fim de conhecer sua representatividade nos cenários nacional e regional.

\section{Caracterizações da agricultura familiar}

O uso da expressão agricultura familiar é uma caracterização atual. De acordo com Schneider (2003), o surgimento dessa expressão no Brasil ocorreu em meados da década de 1990. Abramovay (1997) salienta que, até certo tempo atrás, a agricultura familiar era designada por "pequena produção", "agricultura de subsistência" ou "agricultura de baixa renda", embora sua importância, no cenário econômico e para o ambiente social, não fosse reconhecida.

De acordo com Alves et al. (2009), existe no Brasil uma agricultura heterogênea, subdividida em dois grupos, conhecidos como "agricultura comercial ou patronal", que são as grandes monoculturas com produção voltada para o mercado externo, e a "agricultura familiar", com sua produção voltada basicamente ao mercado interno.

Além do papel produtivo da agricultura familiar, destaca-se também a questão da multifuncionalidade da agricultura, em que ela se torna responsável por diversas funções. Segundo Gaviola e Costa (2011), essas variadas funções podem se traduzir em atividades não agrícolas, como agroindústria familiar, turismo no espaço rural e comercialização direta, ocupações que se originam na agropecuária e na paisagem agrícola e que são estreitamente relacionadas com estas. Porém essas medidas trazem distintas repercussões, umas favoráveis, alegando o fortalecimento da agricultura, e outras contrárias, evidenciando seu enfraquecimento e a necessidade de complementação de renda por parte dos agricultores, mediante rendas agrícolas insuficientes.

$\mathrm{Na}$ abordagem de Moruzzi e Lacerda (2008), é ressaltada a relação da multifuncionalidade com o desenvolvimento sustentável. 
Por meio do apoio de políticas agrícolas, os agricultores podem desempenhar papéis em favor da preservação ambiental, da coesão social, do equilíbrio territorial e da qualidade de alimentos, entre outros.

$\mathrm{Na}$ agricultura familiar, são comuns as práticas de diversificação da produção. Segundo Bianchini (2007), essa diversidade é estabelecida pelo agricultor por conta de alguns fatores, como a possibilidade de obter diferentes rendas, ao longo do ano, para prover garantia do autoconsumo alimentar, de forma que é necessário atentar-se para a sazonalidade das produções, e também as reduções de riscos, assim como a dependência de insumos externos. O autor ainda ressalta que essa diversificação é possível devido ao fato de o agricultor familiar obter disponibilidade de empreender e trabalhar nesses cultivos junto com os demais familiares.

Para Mergarejo Neto (2008,) a diversificação de produção e integração de atividades, pode representar para a agricultura familiar uma opção ideal para a dinamização e desenvolvimento de uma agricultura ambiental e socialmente sustentável. Desse modo, torna-se bastante propício à adesão de práticas sustentáveis pela agricultura familiar, no cultivo de produtos orgânicos devido aos processos de produção adotados nesse tipo de agricultura.

\section{A agricultura familiar e a produção de alimentos orgânicos}

A agricultura moderna, utilizada principalmente em grandes propriedades de produção de maior escala, não tem se mostrado sustentável. Conforme ressalta Oliveira et al (2008), o surgimento de uma nova agricultura "agroecologia" vem apresentado novas perspectivas para viabilizar a produção, preservando o meio ambiente e, ao mesmo tempo, direcionando-se ao caminho da sustentabilidade econômica, social e ambiental. Assim, a agricultura orgânica apresenta-se como uma possibilidade de uma agricultura sustentável.

Dentro do contexto da agricultura familiar, está se tornando cada vez mais comum essa produção de alimentos orgânicos. Conforme aborda Silva et al (2010), por serem produtos isentos da aplicação de agrotóxicos, adubos químicos, antibióticos ou qualquer outro tipo de substância utilizada na produção convencional, os alimentos orgânicos possuem uma série de benefícios, sobretudo para a saúde humana, além de reduzir expressivamente os impactos negativos que um cultivo convencional de alimentos traz ao meio ambiente.

Lago et al. (2006) salientam que, devido às dificuldades frente aos problemas econômi$\cos$, sociais e ambientais, muitos agricultores buscam empreender novas práticas agroecológicas. Geram, dessa forma, uma agregação de valor a esses produtos, pela diferenciação ecológica e atendem a demanda de um mercado que visa consumir esse alimento de maior qualidade.

Tendo em vista as vantagens ao consumir os alimentos orgânicos, tanto para a saúde humana quanto para o ambiente, por receber um novo tratamento por meio das bases agroecológicas, a viabilidade econômica desse mercado encontra-se em considerável ascensão, favorecendo o aumento da produção e melhorando a renda dos agricultores. Buainain (2003) ressalta que a crescente demanda por produtos orgânicos possibilita a expansão e geração da renda para os produtores familiares.

Diante da necessidade da diversificação da produção pelos pequenos produtores, Beltrão (2002) destaca a facilidade e a melhor adaptação por esses agricultores aos princípios da agricultura orgânica, sobretudo pela indução do equilíbrio ecológico, reciclagem de nutrientes, insumos caseiros, conservação do solo e controle de pragas e doenças de maneira ecológica. A utilização de insumos próprios e naturais na cultura acarreta também uma diminuição nos custos de produção, tornando-a mais lucrativa ao produtor.

Apesar dos vastos benefícios que cercam o consumo de alimentos orgânicos, e mesmo com a expansão gradativa desse mercado, muitos consumidores ainda optam por adquirir os produtos convencionais. Essa condição pode estar relacionada ao preço dos produtos orgânicos, por serem mais elevados em comparação aos alimentos convencionais. De acordo com estudos realizados por Mesquita (2006), esse fator de consumo é determinado pelo nível de instrução dos consumidores, ao constatar que pessoas mais instruídas, com maior acesso à informação e poder aquisitivo 
razoável são os maiores consumidores desses produtos, o que de fato os caracteriza como um grupo de consumidores diferenciados e mais exigentes.

\section{Metodologia}

Este estudo trata-se de uma pesquisa exploratória. De acordo com Gil (2009, p. 27): “As pesquisas exploratórias têm como principal finalidade desenvolver, esclarecer e modificar conceitos e idéias, tendo em vista a formulação de problemas mais precisos ou hipóteses pesquisáveis para estudos posteriores". Quanto à coleta de dados, foram empregados procedimentos de pesquisa bibliográfica e documental, sobre a qual Silva (2003, p. 60) salienta que "Pesquisa bibliográfica explica e discute um tema ou problema com base em referências teóricas já publicadas em livros, revistas, periódicos, artigos científicos". A pesquisa documental assemelha-se muito à pesquisa bibliográfica. Conforme Gil (2009), na pesquisa documental são utilizados materiais que não receberam tratamento analítico ou podem também ser reelaborados de acordo com os objetos da pesquisa.

Dessa forma, esta pesquisa foi realizada com base nos últimos censos agropecuários divulgados pelo IBGE, nos anos de 1996 e 2006, sendo realizado também, um levantamento bibliográfico referente à produção familiar e orgânica do Brasil e do estado de Mato Grosso do Sul.

As fontes de dados foram buscadas em materiais impressos, tais como artigos científicos, teses, dissertações e livros, além de consultas a sites oficiais de Agências Governamentais (IBGE, INCRA, IPEA, MDA) e sites inerentes aos produtos orgânicos.
Vale destacar, no entanto, que o critério adotado pelo MDA e pelo IBGE, no Censo Agropecuário, para definir agricultura familiar - Lei 11.326/2006 - é mais restrito em relação aos critérios adotados pela metodologia estabelecida pelo Projeto de Colaboração Técnica entre a FAO e o INCRA, de modo que houve algumas implicações nos resultados por conta dessas diferenças. Neste trabalho, será considerada a metodologia FAO/INCRA para confrontar os dados da Agricultura Familiar entre os dois Censos Agropecuários.

\section{Resultados e discussões}

A agricultura familiar no Brasil e no estado de Mato Grosso do Sul

No Censo Agropecuário realizado em 1996, conforme dados da Tabela 1, foram identificados no Brasil 4.139.369 estabelecimentos da agricultura familiar, representando um total de $85 \%$ dos estabelecimentos identificados, os quais ocupavam uma área de 107,8 milhões de ha, totalizando apenas 30\% da área total. A mão de obra utilizada na agricultura familiar também se mostra relevante, ao empregar 13.780.201 pessoas, ou seja, $77 \%$ do total. Esse fator deixa evidente a valorização de aspectos sociais devido à inserção do homem na atividade rural, o que opostamente não ocorre na agricultura não familiar, que, ao utilizar maior área para os cultivos de acordo com uma proporção de $70 \%$, utiliza-se de pouca mão de obra na produção, com um total de $23 \%$. Normalmente isso ocorre por conta das inovações tecnológicas, uma vez que, com a mecanização, a demanda por mão de obra no cultivo reduz.

Tabela 1 - Características dos estabelecimentos agropecuários, segundo a classificação de agricultura familiar e não familiar - Brasil 1996

\begin{tabular}{l|ccccc}
\hline \multirow{2}{*}{\multicolumn{1}{c|}{ Características }} & \multicolumn{2}{|c|}{ Agricultura Familiar } & \multicolumn{2}{c}{ Não Familiar } \\
\cline { 2 - 5 } & Valor & Percentual & Valor & Percentual \\
\hline Número de estabelecimentos & 4.139 .369 & 85 & 720.363 & 15 \\
Área (milhões ha) & 107,8 & 30 & 245,8 & 70 \\
Mão de obra (milhões de pessoas) & 13,7 & 77 & 3,05 & 23 \\
\hline
\end{tabular}

Fonte: Adaptado de IBGE - Censo Agropecuário (1996). 
A partir do último Censo Agropecuário realizado em 2006, foram identificados no Brasil 4.367.902 estabelecimentos da agricultura familiar, representando $84 \%$ dos estabelecimentos brasileiros, conforme demonstrado na Tabela 2, que também revela a pouca área ocupada pelos agricultores familiares, resultando em um total de apenas $24 \%$ desse território. Percebe-se também a relevância da agricultura familiar na geração de emprego, dada a utilização de $74 \%$ do total de mão de obra na agricultura.

Tabela 2 - Características dos estabelecimentos agropecuários, segundo a classificação de agricultura familiar e não familiar - Brasil 2006.

\begin{tabular}{l|ccc|c}
\hline \multirow{2}{*}{\multicolumn{1}{c|}{ Características }} & \multicolumn{2}{|c|}{ Agricultura Familiar } & \multicolumn{2}{c}{ Não Familiar } \\
\cline { 2 - 5 } & Valor & Percentual & Valor & Percentual \\
\hline Número de estabelecimentos & 4.367 .902 & 84 & 807.587 & 16 \\
Área (milhões ha) & 80,3 & 24 & 249,7 & 76 \\
Mão de obra (milhões de pessoas) & 12,3 & 74 & 4,2 & 26 \\
\hline
\end{tabular}

Fonte: Adaptado de IBGE - Censo Agropecuário (2006)

A partir de uma análise comparativa, considerando os dois Censos, percebe-se que, do total dos estabelecimentos agropecuários, houve um crescimento de 5,5\% na agricultura familiar e de $12,1 \%$ na não familiar. Em relação à área (ha), a agricultura familiar obteve uma queda de $25,5 \%$, e a não familiar cresceu somente $1,6 \%$. Com relação a mão de obra, houve também uma pequena redução nos percentuais apontados em 2006 na agricultura familiar, demonstrando um declínio de 10,2\%, sendo que, em contrapartida, a agricultura não familiar apresentou um aumento de $37,7 \%$. Contudo, mediante essas reduções, a agricultura familiar mostra-se capaz de reter proporcionalmente maior número de empregos e manter seu nível de crescimento, mesmo com a redução de suas áreas e mão de obra empregada.
No estado de Mato Grosso do Sul, o Censo Agropecuário de 1996 identificou 26.789 estabelecimentos da agricultura familiar, representando um total de $58 \%$ dos estabelecimentos identificados e que ocupavam uma área de 2.083.047 ha, o que totaliza apenas $7 \%$ do total da área no estado. Quanto ao número de mão de obra utilizada na agricultura familiar em Mato Grosso do Sul, foram identificadas 82.606 pessoas empregadas nesse setor, correspondendo a $43 \%$ sobre o total. Com relação à agricultura não familiar, foram identificados no Mato Grosso do Sul 19.225 estabelecimentos, correspondente a $42 \%$ do total, assim como ocupação de $93 \%$ da área agricultável, o que caracteriza uma alta taxa de concentração de terras no estado. Foi constatado também que a agricultura não familiar absorvia nesse período $57 \%$ de mão de obra na atividade (Tabela 3 ).

Tabela 3 - Características dos estabelecimentos agropecuários, segundo a classificação de agricultura familiar e não familiar Mato Grosso do Sul em 1996

\begin{tabular}{l|ccc|c}
\hline \multirow{2}{*}{ Características } & \multicolumn{2}{|c|}{ Agricultura Familiar } & \multicolumn{2}{c}{ Não Familiar } \\
\cline { 2 - 5 } & Valor & Percentual & Valor & Percentual \\
\hline Número de estabelecimentos & 26.789 & 58 & 19.225 & 42 \\
Área (ha) & 2.083 .047 & 7 & 28.670 .848 & 93 \\
Mão de obra (pessoas) & 82.606 & 43 & 110.829 & 57 \\
\hline
\end{tabular}

Fonte: Adaptado de IBGE - Censo Agropecuário (1996). 
Segundo o Censo Agropecuário de 2006 (Tabela 4), o número de estabelecimentos identificados como sendo da agricultura familiar foi de 41.104 , passando a representar $63 \%$ dos estabelecimentos do estado, entretanto a área abrangida por esses estabelecimentos sofre redução, totalizando 1.190.206 ha, o que corresponde a $4 \%$ do total. A mão de obra utilizada passa a representar $46 \%$ do total de pessoas ocupadas na agricultura, sendo que, embora estando menor que o índice nacional, representa um indicativo significante na geração de emprego no meio rural.

Tabela 4 - Características dos estabelecimentos agropecuários, segundo a classificação de agricultura familiar e não familiar - Mato Grosso do Sul em 2006

\begin{tabular}{l|ccc|c}
\hline \multirow{2}{*}{ Características } & \multicolumn{2}{|c|}{ Agricultura Familiar } & \multicolumn{2}{c}{ Não Familiar } \\
\cline { 2 - 5 } & Valor & Percentual & Valor & Percentual \\
\hline Número de estabelecimentos & 41.104 & 63 & 23.758 & 37 \\
Área (ha) & 1.190 .206 & 4 & 28.866 .741 & 96 \\
Mão de obra (pessoas) & 97.431 & 46 & 113.760 & 54 \\
\hline
\end{tabular}

Fonte: Adaptado de FRANÇA, C. G.; DEL GROSSI, M. E.; MARQUES, V. P. A. (2009). O Censo Agropecuário 2006 e a Agricultura Familiar no Brasil. Brasília: MDA, 2009.

A partir de uma análise comparativa entre os dois Censos, percebe-se nitidamente o avanço da agricultura familiar em Mato Grosso do Sul, com incremento de $53,4 \%$ no número de estabelecimentos, assim como acréscimo de $23,6 \%$ da agricultura não familiar. Contudo a área da agricultura familiar sofre uma acentuada redução de $42,8 \%$, enquanto a agricultura não familiar tem pequeno acréscimo de $0,68 \%$. Com relação a mão de obra, a agricultura familiar mostra aumento de $17,9 \%$, enquanto a não familiar apresenta crescimento de $2,6 \%$, o que destaca a eficiência da agricultura familiar na geração de emprego.

Quanto ao PIB (Produto Interno Bruto), cabe destacar que, conforme Guilhoto et al (2007), o peso da participação da agricultura familiar para a geração de riqueza no país, chegou a $10 \%$ do PIB nacional entre 1995 a 2005, o que corresponde a um terço do total das cadeias produtivas do mesmo período. De acordo com o Gráfico 1, é feita uma análise do PIB nacional entre os anos de 1995 a 2005, na qual a participação do agronegócio familiar no PIB do Brasil correspondia a 9\% em 2005, representando uma queda em relação a 2003, em que sua participação era de $10,1 \%$, o maior índice durante todo o período analisado. Queda que também atingiu o agronegócio patronal, o qual, em 200,5 correspondia a $18,9 \%$ e, em 2003 , a $20,5 \%$. 


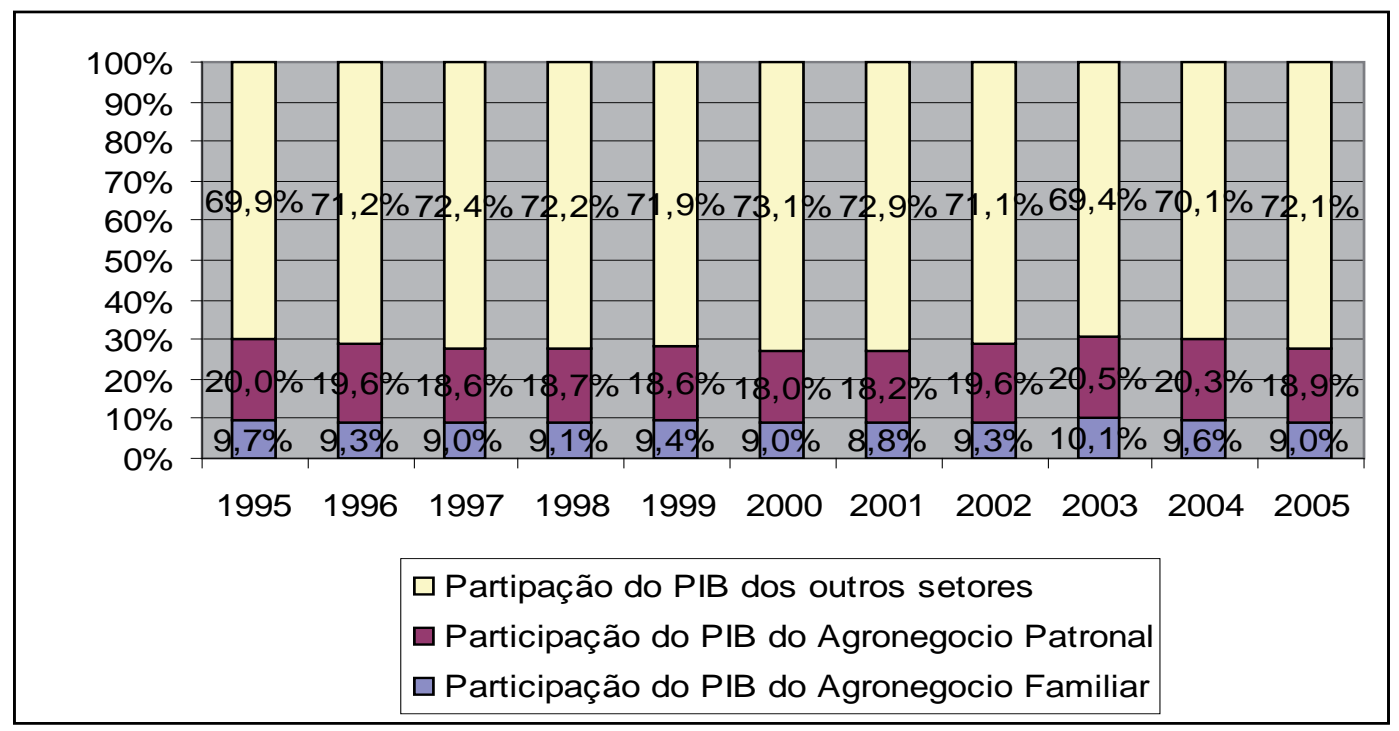

Gráfico 1 - Participação do PIB do agronegócio familiar e patronal no PIB do Brasil entre 1995 a 2005.

Fonte: Adaptado de GUILHOTO, J. J. M. et al. PIB da agricultura familiar: Brasil/Estados (2007).

Quanto ao PIB de Mato Grosso do Sul, o segmento familiar apresentou um aumento gradativo a cada ano. No ano de 2004, o PIB da agricultura familiar totalizou-se em $\mathrm{R} \$$ 3.465 .728 , o que corresponde a $16.20 \%$ do PIB estadual. Somente a lavoura apresentou uma queda em 2004, mas se recuperou em 2005 com um aumento de 16,1\% no período.
Já a pecuária, embora não tenha tido nenhum declínio durante o período analisado, obteve um crescimento em 12,3\% de 2004 para 2005, sendo que este foi o menor índice durante o período compreendido entre 2002 a 2005, já que, entre 2003 a 2004, o crescimento da pecuária foi de $30 \%$ e, entre 2002 a 2003, foi de $16 \%$ (Tabela 5).

Tabela 5 - PIB do agronegócio familiar em Mato Grosso do Sul, no período de 2002 a 2005 (valores em mil R\$).

\begin{tabular}{l|c|c|c|c}
\hline \multicolumn{1}{c|}{ Ano } & $\mathbf{2 0 0 2}$ & $\mathbf{2 0 0 3}$ & $\mathbf{2 0 0 4}$ & $\mathbf{2 0 0 5}$ \\
\hline PIB Total do estado MS & 20.453 .978 & 22.009 .400 & 21.392 .638 & - \\
\% PIB do Agronegócio Familiar & $12,15 \%$ & $13,62 \%$ & $16,20 \%$ & - \\
PIB do Agronegócio Familiar & 2.484 .698 & 2.997 .278 & 3.465 .728 & 3.929 .233 \\
Lavoura & 828.290 & 1.073 .261 & 964.949 & 1.120 .395 \\
Pecuária & 1.656 .408 & 1.924 .017 & 2.500 .779 & 2.808 .838 \\
\hline
\end{tabular}

Fonte: GUILHOTO, J. J. M. et al. PIB da agricultura familiar: Brasil - Estados. MDA/NEAD, 2007. p. 148.

Conforme análises de Guilhoto et al (2007), durante o período de 1995 a 2005, constatou-se uma forte tendência pela criação de aves e produção leiteira pela agricultura familiar no Brasil, porém a avicultura apresentou um maior crescimento no período tanto na agricultura familiar, quanto na patronal. No Centro-Oeste, a participação da agricul- tura familiar no PIB nacional correspondia a $7 \%$ em 2004, sendo que as regiões Sul e Sudeste despontavam à frente com $43 \%$ e $24 \%$, respectivamente, durante esse período. Esse índice identificado na região Centro-Oeste é ocasionado pela significativa produção destinada ao mercado externo, já que nessa região é muito comum um agronegócio de caráter 
patronal, no qual a maior parte do PIB dos estados de Mato Grosso e Goiás concentramse na produção de grãos. No estado de Mato Grosso do Sul, sobressai a pecuária bovina com peso significativo no PIB do agronegócio, que vem sendo incrementado também com lavouras de cana devido à implantação de novas usinas de açúcar e álcool na região (GUILHOTO et al, 2007).

\subsection{A produção de alimentos orgânicos no Brasil e no estado de Mato Grosso do Sul}

Sabendo da importância de se utilizar as práticas agrícolas baseadas nos princípios da agroecologia além de uma maior atenção aos cuidados à saúde, a procura por alimentos orgânicos no Brasil e no mundo tem se mostrado crescente nos últimos anos, sobretudo a uma classe diferenciada de consumidores, em sua grande maioria, de alta renda (FONSECA, 2005).

Existem no Brasil inúmeros sistemas de produção de base ecológica que comercializam seus produtos. Mas, para que isso ocorra, é necessário atentar-se à Lei da Produção Orgânica n. 10.831, de 23 de dezembro de 2003, abrangendo dentro deste conjunto desde as variedades de produção que realizam apenas a substituição de insumos (químicos por orgânicos) até os que se orientam pelos princípios da agroecologia. Nesse sentido, Abreu et al (2009) abordam que a agroecologia, mediante sua importância, tem sido uma fonte de inspiração para a formulação de políticas públicas para a agricultura familiar, a qual se mostra suscetível a mudanças e melhor adequabilidade à transição em rumo da sustentabilidade.

O Brasil é o maior consumidor de produtos orgânicos da América Latina, e esse consumo não chega a $1 \%$ do mercado de alimentos. Entretanto boa parte dessa produção é adquirida pelo mercado internacional, sobretudo Japão, Estados Unidos e União Europeia. Dessa forma, as exportações giram em torno de $70 \%$ da produção orgânica nacional, sendo que $80 \%$ de toda a produção é derivada da agricultura familiar, e $20 \%$, da agricultura patronal. Essa comercialização movimenta em torno de 250 milhões de dólares anualmente (ABREU et al, 2009).

Pela primeira vez, o Censo Agropecuário 2006 divulga os resultados da agricultura orgânica no Brasil, buscando conhecer e quantificar os estabelecimentos em que eram adotadas as práticas de produção agropecuária sem utilização de insumos artificiais ou outra medida para a conservação dos recursos naturais e ambientais.

Conforme as investigações do Censo nos estabelecimentos brasileiros, fora constatada uma baixa utilização da agricultura orgânica pelos agricultores. De acordo com a Tabela 6, foram identificados apenas 90.497 estabelecimentos com produção orgânica, correspondendo a 1,7\% do total, com destaque para a Região Nordeste, totalizando 42.236 estabelecimentos com agricultura orgânica, $\mathrm{O}$ que corresponde a $46,6 \%$ dos estabelecimentos que fazem uso da agricultura orgânica no país; no entanto, representa apenas 1,72\% dos estabelecimentos agrícolas identificados na região. Em seguida, sobressai a Região Sul com $21,3 \%$ no total de produção orgânica, mas, em relação ao total de estabelecimentos na região, atinge 1,91\%. No entanto a Região Centro-Oeste apresentou apenas 4.138 estabelecimentos que utiliza a agricultura orgânica, o que corresponde a $4,6 \%$ dos estabelecimentos nacionais que fazem uso dessa prática, entretanto, ao comparar esse dado com o total de estabelecimentos da identificados na região, esse índice cai para 1,3\%. 
Tabela 6 - Uso de agricultura orgânica nos estabelecimentos do Brasil - 2006.

\begin{tabular}{l|c|c|c|c|c}
\hline \multirow{2}{*}{$\begin{array}{c}\text { Brasil, Grandes } \\
\text { Regiões e Unidades } \\
\text { da Federação }\end{array}$} & $\begin{array}{c}\text { Total de } \\
\text { estabelecimentos }\end{array}$ & Total & $\begin{array}{c}\text { Uso de agricultura orgânica nos estabelecimentos } \\
\text { certificado } \\
\text { por entidade } \\
\text { credenciada }\end{array}$ & $\begin{array}{c}\text { Utiliza e não } \\
\text { é certificado } \\
\text { por entidade } \\
\text { credenciada }\end{array}$ & $\begin{array}{c}\text { Não } \\
\text { utiliza }\end{array}$ \\
\hline Brasil & 5.175 .489 & 90.497 & 5.106 & 85.391 & 5.084 .992 \\
\hline Norte & 475.775 & 6.133 & 351 & 5.782 & 469.642 \\
Nordeste & 2.454 .006 & 42.236 & 1.218 & 41.018 & 2.411 .770 \\
Sudeste & 922.049 & 18.715 & 1.366 & 17.349 & 903.334 \\
Sul & 1.006 .181 & 19.275 & 1.924 & 17.351 & 986.906 \\
\hline Centro-Oeste & 317.478 & 4.138 & 247 & 3.891 & 313.340 \\
\hline Mato Grosso do Sul & 64.862 & 753 & 31 & 722 & 64.109 \\
Mato Grosso & 112.978 & 1.619 & 79 & 1.540 & 111.359 \\
Goiás & 135.683 & 1.605 & 113 & 1.492 & 134.078 \\
Distrito Federal & 3.955 & 161 & 24 & 137 & 3.794 \\
\hline
\end{tabular}

Fonte: Adaptado de IBGE, Censo Agropecuário (2006).

O estado de Mato Grosso do Sul apresentou 753 estabelecimentos que usam a agricultura orgânica, o que corresponde a $18,2 \%$ dos estabelecimentos da região que utilizam essa prática. Com relação aos demais estabelecimentos do estado, a agricultura orgânica em Mato Grosso do Sul representa $1,16 \%$, correspondendo apenas a $0,8 \%$ dos estabelecimentos produtores de orgânicos a nível nacional. Cabe salientar nesta análise que, dentre os estabelecimentos que fazem uso da agricultura orgânica, 95,8\% não utilizam a certificação dos produtos por entidade credenciada, o que pode ser justificada pelos custos que este procedimento pode gerar.

Com relação aos grupos de atividade econômica (Tabela 7), é evidenciada a predominância da pecuária e a criação de outros animais na produção orgânica, assim como a produção de lavouras temporárias. As demais variedades aparecem em menores quantidades, como a produção de lavouras permanentes e a horticultura e floricultura, cuja representatividade em nível nacional encontra-se em $4,5 \%$ com relação ao total de estabelecimentos dessa categoria, sendo este o segmento de maior importância quando comparado aos demais grupos de atividade econômica.

Tabela 7 - Distribuição dos estabelecimentos produtores de orgânicos, segundo os grupos de atividade econômica - Brasil 2006.

\begin{tabular}{l|rrr}
\hline \multirow{2}{*}{ Grupos da atividade econômica } & \multicolumn{2}{c}{ Estabelecimentos } \\
\cline { 2 - 4 } & \multirow{2}{*}{ Total } & \multicolumn{2}{c}{ Produtores de orgânicos } \\
\cline { 2 - 4 } Total & 5.175 .489 & 90.497 & 1,75 \\
\hline Produção de lavouras temporárias & 1.908 .654 & 30.168 & 1,58 \\
Horticultura e floricultura & 200.379 & 8.900 & 4,44 \\
Produção de lavouras permanentes & 558.587 & 9.557 & 1,71 \\
Produção de sementes, mudas e outras formas & 2.682 & 52 & 1,94 \\
de propagação vegetal & & 1,67 \\
Pecuária e criação de outros animais & 2.277 .211 & 38.014 & 2,2 \\
Produção florestal - florestas plantadas & 74.344 & 1.638 & 1,3 \\
Produção florestal - florestas nativas & 126.649 & 1.644 & 1,02 \\
Pesca & 15.072 & 153 & 3,11 \\
Aquicultura & 11.911 & 371 & \\
\hline
\end{tabular}

Fonte: Adaptado de IBGE, Censo Agropecuário (2006). 
O Censo também destacou que, no Brasil, em 2006, o perfil do agricultor que se dedicava à agricultura orgânica era, na grande maioria, composta por proprietários de terras exploradas (77,3\%). Quanto ao nível de instrução, $41 \%$ possuíam nível fundamental incompleto, e $22 \%$ não sabiam ler e escrever. Já em relação ao nível de organização social dos agricultores, foi revelado que $54 \%$ deles não participavam de nenhuma organização social. Dentre os que possuíam algum vínculo organizacional, $36,6 \%$ dos produtores eram vinculados a associações, sindicatos e outros, já os que eram organizados em cooperativas representavam apenas 5,9\% dos agricultores dedicados à agricultura orgânica. Resultados que mostram como a organização entre os agricultores é precária, dado que implica diretamente no fortalecimento e estruturação deste setor.

\section{Considerações finais}

A partir deste estudo, foi possível constatar a importância da agricultura familiar para o desenvolvimento nacional, assim como regional, ao destacar por meio dos dados analisados, a sua importância em um contexto socioeconômico. A expansão da agricultura familiar, revelada pelo Censo, no Brasil e no estado de Mato Grosso do Sul, tem gerado bons resultados para a economia brasileira, com o aumento da renda dos agricultores, do que tem decorrido inclusão social, melhor qualidade de vida, assim como geração de empregos.

Quanto ao PIB da agricultura familiar, pôde-se constatar que, em nível nacional, os percentuais mantiveram-se constantes, entretanto o estado de Mato Grosso do Sul apresentou melhores resultados com um crescimento consecutivo entre os períodos analisados. No entanto, pôde-se observar que, tanto no Brasil, como no estado de Mato Grosso do Sul, o nível de utilização da agricultura orgânica é muito baixo, o que pode ser entendido pela falta de incentivo e orientação adequada aos pequenos produtores a aderirem essa prática. Contudo é importante destacar o papel das políticas públicas para o desenvolvimento desse setor, de forma que continue avançando em cada programa, tendo condições de orientar e atender todas as necessidades da agricultura familiar de maneira mais eficiente. Em suma, destaque-se a importância da agricultura familiar para o desenvolvimento socioeconômico e a necessidade de intensificação das políticas públicas voltadas para a disseminação de métodos agroecológicos no cultivo, basicamente em virtude dos benefícios sociais, econômicos e ambientais gerados por essa prática. Ressalta-se também, a necessidade de estudos com dados mais recentes quanto à agricultura familiar e produção orgânica, a fim de conhecer a atual realidade desses segmentos e medir de forma mais aprofundada suas contribuições para o desenvolvimento socioeconômico nacional e regional.

\section{Referências}

ABRAMOVAY, R. Agricultura familiar e uso do solo. São Paulo em Perspectiva, São Paulo, v. 11, n. 2, p. 73-78, 1997.

ABREU, L. S.; KLEDAL, P.; PETTAN, K. ; RABELLO, F.; MENDES, S. C. Trajetória e situação atual da agricultura de base ecológica no Brasil e no Estado de São Paulo. Cadernos de Ciência E Tecnologia, Brasília, v. 26, p. 149-178, 2009.

ALVES, J. ; FIGUEIREDO, A. M. R.; BOUNJOUR, P. D. S. C. M.; GOMES, M. B. A agricultura familiar em Mato Grosso. Revista Eletrônica Documento e Monumento, Cuiabá, v. 1, p. 69-86, 2009.

BELTRÃO, N. E. M. Agricultura orgânica e seu potencial como estratégia de produção. In: SIMPÓSIO NACIONAL SOBRE AS CULTURAS DO INHAME E DO TARO, 2.,2002, João Pessoa. Anais... João Pessoa, 2002, p. 71-94.

BIANCHINI, V. O universo da agricultura familiar e sua contribuição ao desenvolvimento rural. 2007. Disponível em: <http:/ / redeagroecologia.cnptia.embrapa.br/ biblioteca/agricultura-familiar>. Acesso em: 08 maio 2012.

BUAINAIN, A. M.; ROMEIRO, A. R.; GUANZIROLI, C. Agricultura familiar e o novo mundo rural. Sociologias, Porto Alegre, v. 5, n. 10, p. 312-347, 2003.

CAUME, D. J. Segurança alimentar, reforma agrária e agricultura familiar. Revista Extensão e Cultura, Goiânia, v. 1, p. 36-39, 2003.

FONSECA, M. F. A. C. A institucionalização dos mercados de orgânicos no mundo e no Brasil: uma interpretação. 2005. 476 p. Tese (Doutorado em Sociologia) - UFRJ, ICHS, CPDA, Seropédica, 2005.

FRANÇA, C. G.; DEL GROSSI, M. E.; MARQUES, V. P. A. O censo agropecuário 2006 e a agricultura familiar no Brasil. Brasília: MDA, 2009. 96 p.

GAVIOLA, F. R.; COSTA, M. B. P. As múltiplas funções da agricultura familiar: um estudo no assentamento Monte Alegre, região de Araraquara (SP). Revista de Economia e Sociologia Rural, v. 49, n. 2, p. 449-472, 2011. 
GIL, A. C. Métodos e técnicas de pesquisa social. 6. ed. São Paulo: Atlas, 2009.

GOMES, I. Sustentabilidade social e ambiental na agricultura familiar. Revista de biologia e ciência da terra, v. 5, n. 1, 2004.

GUILHOTO, J. J. M. et al. PIB da Agricultura Familiar: Brasil - Estados. Ministério do Desenvolvimento Agrário (MDA). NEAD Estudos 19. Brasília, 2007.172 p. Disponível em: <http:/ / portal.mda.gov.br/portal/ saf/arquivos/view/ater/livros/PIB-AFamiliar_x_Patronal-2002-2005.pdf>. Acesso em: 26 jun. 2012.

GUILHOTO, J. J.; SILVEIRA, F. G.; ICHIHARA, S. M.; AZZONI, C. R. A importância do agronegócio familiar no Brasil e seus estados. RER, v. 44, n. 03, p. 355-382, 2006.

IBGE. Censo Agropecuário 1995/96. Brasília, 1996. Disponível em: <http://www.ibge.gov.br/home/estatistica/economia/agropecuaria/censoagro/1995_1996/ default.shtm>. Acesso em: 20 jun. 2012.

IBGE. Censo Agropecuário 2006. Brasília, 1996. Disponível em: <http://www.ibge.gov.br/home/estatistica/ economia/agropecuaria/censoagro/default.shtm>. Acesso em: 20 jun. 2012.

IPEA. Fiscais da saúde dos alimentos - Empresa de Botucatu é exemplo de certificadora de produtos orgânicos. Disponível em: <http://desafios.ipea.gov.br/ index.php?option $=$ com_content\&view $=$ article\&id $=1$ 417: catid=28\&Itemid=23>. Acesso em: 24 maio 2012.

LAGO, A.; LENGLER, L.; CORONEL, D. A.; SILVA, T. N. Agricultura familiar de produtos orgânicos: um olhar sob a ótica do marketing. Revista de Extensão Rural, v. 13, p. 96-119, 2006.
MESQUITA, Z. Agricultores e consumidores de produtos orgânicos: uma aproximação necessária. Rev. Bras. de Agroecologia, v. 1, n. 1, 2006.

MORUZZI, P. M.; LACERDA, T. F. N. Agricultura orgânica, representação territorial e reprodução social da agricultura familiar: os agricultores ecologistas da Encosta da Serra Geral em Santa Catarina. Ruris, Campinas, v. 2, p. 137-158, 2008.

MERGAREJO NETTO, M. A. Agricultura familiar e sua organização. Revista Acta Geográfica, ano 2, n. 4, p. 17-30, 2008.

OLIVEIRA, A. F. S.; KHAN, A. S.; LIMA, P. V.; SILVA, L. M. R. A Sustentabilidade da agricultura orgânica familiar dos produtores associados à APOI (Associação dos Produtores Orgânicos da Ibiapaba-CE). In: SOCIEDADE BRASILEIRA DE ECONOMIA, ADMINISTRAÇÃO E SOCIOLOGIA RURAL, 16., 2008, Rio Branco. Anais... Amazônia, mudanças globais e agronegócio: o desenvolvimento em questão. Brasília: SOBER, 2008, v. 1 , p. 1-20.

SCHNEIDER, S. Teoria social, agricultura familiar e pluriatividade. Revista Brasileira de Ciências Sociais, v. 18, n. 51, 2003.

SILVA, A. C. R. Metodologia da pesquisa aplicada a Contabilidade. São Paulo: Atlas, 2003.

SILVA, F. Q. P. O. ; FOSCACHES, C. A. L; LIMA FILHO, D. O. O perfil do consumidor de produtos orgânicos na cidade de Campo Grande-MS. In: Semead Seminários em Administração - Sustentabilidade Ambiental nas organizações, 13., 2010, Anais... São Paulo, p. 1-20. 